\title{
L.-The Amount of Nitric Acid in the Rain-water at Rothamsted, with Notes on the Analysis of Rain-water.
}

\section{By R. WARINGTON, F.R.S.}

THE earliest analyses of the rain-water at Rothamsted published by Lawes and Gilbert (Brit. Ass. Report, 1854), do not include the determination of nitric acid; attempts were indeed made to determine the amount present, but the method used proved inadequate for this purpose. Way subsequently determined the nitric acid in samples of Rothamsted rain-water, representing the rainfall of each month in 1855 and 1856 (J. Roy. Agri. Soc., 1856, 142, 618; 1886, 12). To accomplish these determinations he made use of the reaction proposed by Bunsen: the residue obtained by evaporating the rain with lime-water was heated with potassinm iodide and hydrochloric acid in a flask free from oxygen, and the liberated iodine determined. By this process he obtained a mean of 0.12 of nitrogen as nitric acid per million of water, the extreme amounts in the rainfall of any month being 0.06 and 0.30 per million. The total quantity of nitric nitrogen in the rainfall of each year was respectively $0.72 \mathrm{lb}$. and $0.76 \mathrm{lb}$. per acre.

In 1869 and 1870, Dr. E. Frankland examined 71 samples of rainwater from Rothamsted for nitric acid. He found that his usual method (the production of nitric oxide gas by the action of the water residue mixed with sulphuric acid upon mercury) failed to show the presence of nitric acid. Thirty-four of the samples of rain-water were, however, examined by the aluminium method, and in each case nitric acid was found. The arithmetical mean of these 34 analyses gives 0.14 of nitrogen as nitric acid per million of water, the extremes being 0.01 and 0.44 per million. In samples of dew, a maximum of 0.50 was obtained. As the samples of rain examined did not represent the whole rainfall of any period, they do not afford material for calculating the average composition of rain-water; the mean result of the 34 analyses agrees, however, substantially with the earlier results obtained by Way.

In recent years, new determinations of the ammonia, chlorine, and sulphuric acid in rain-water have been made at the Rothamsted Laboratory (Trans., 1887, 501); we have now to record similar results relating to nitric acid.

The rain-water employed, as in all the determinations already noticed, was collected in a large leaden gauge, having an area of 1-1000th of an acre. Of the daily collection of rain, dew, or snow-

voL. LV. 
water, a fixed fraction (a gallon for each inch) was placed in a carboy; at the end of each month the contents of the carboy was mixed, and a sample taken for analysis. In the carboy receiving the rain for nitric acid estimation, a little mercuric chloride was placed each month, with the view of preventing any change of ammonia into nitric acid; it may be doubted, however, if this precaution was necessary, as the rain-water always contained a very appreciable amount of lead, and earlier experiments (J. Roy. Agri. Soc., 1883, $319)$ showed that on the whole the rain-water more frequently gained than lost ammonia by keeping.

The method first employed was to concentrate $10 \mathrm{lbs}$. of the rainwater in a retort, a little magnesia being added to decompose any ammonium nitrite or nitrate present. The concentration was conducted in a retort, as earlier experiments had shown (Trans., 1881, 229) that evaporation in the open air, and especially over gas, resulted in a distinct addition to the nitrites present. When concentrated to a small bulk, the water was filtered, and then evaporated nearly to dryness in a very small beaker. The nitrogen as nitrates and nitrites was then determined by the improved form of Schloesing's method already described (Trans., 1882, 345), the amount of nitric nitrogen being ascertained by measurement of the nitric oxide gas obtained.

My own experiments had shown Schloesing's method to be susceptible of great accuracy, and to be quite unaffected by the presence of organic matter. Suspicion was, however, aroused that nitrates were lost during the final stage of concentration of the water. In some cases, depending apparently on the amount of organic matter present, a heavy black deposit, probably of reduced lead, was formed when the water reached a small bulk, and from this deposit bubbles of gas were continuously evolved. Fearing the reduction of nitrates, I sought to control the results by some method in which the concentration of the water should be unnecessary. The aluminium method seemed open to objection, as it involved the addition of much sodium or potassium hydrate, which would probably react on the nitrogenous organic matter in the rain-water and produce ammonia. I resolved, therefore, to try the copper-zinc couple, following the plan proposed by M. W. Williams (Trans., 1881, 100).

In the experiments first made, ammonia was determined in one portion of the rain-water; the nitrates and nitrites were then reduced by means of the couple in another portion of the water, and ammonia again determined; from the difference in the quantity of ammonia found in the first and second determination, the quantity of nitrogen originally present as nitrates and nitrites was calculated. This mode of proceeding was soon rejected as admitting of little exactness. As 
the determinations of ammonia were made by Nesslerising, the quantity of ammonia present in the second determination was necessarily small, and the greater part of this consisted of the ammonia originally present in the rain; the errors of two determinations thus fell on the very small amount of ammonia representing the nitrates and nitrites in the water.

The method finally adopted was to boil rapidly I litre of the rainwater in a retort, with a little magnesia (previously raised to a low red heat and then washed), till 250 c.c. had distilled over. The residue was then made up to 800 c.c., transferred to a wide-mouthed stoppered bottle, supplied with strips of zinc foil converted into couple, and placed in an incubator at $21-24^{\circ}$ for three days.* A measured portion of the solution was then distilled, and the ammonia in the distillate determined.

This plan had two advantages: 1 . The ammonia, as well as the nitrogen as nitrates and nitrites, could be determined in the course of the same operation, and in the same sample of water. For this purpose it was only necessary to fit the retort to an efficient condenser, and to remove all ammonia from the apparatus by boiling distilled water in the retort before introducing the rain-water. The distillate of 250 c.c. afterwards obtained was well mixed, and the ammonia present determined in 25,50 , or 100 c.c., diluted to 150 c.c. with water free from ammonia. 2. The nitrogen as nitrates and nitrites was determined directly and alone; the error of the determination was also as small as Nesslerising admits of, since it was possible, if necessary, to distil 600 c.c. of the boiled rain-water (corresponding to 750 c.c. of original rain), and thus obtain a full amount of ammonia for determination, even when the rain had been poor in nitrates.

Some of the monthly samples of rain-water were analysed both by the Schloesing and by the copper-zinc method, with the results given in the next table.

On comparing the results given by the two methods, it appears that in a number of cases the differences shown are very small; whilst in fewer instances, generally where the rain-water is of a more concentrated character, the copper-zinc method shows a considerably larger amount of nitric acid. In 11 samples of rain, the mean amount of nitric nitrogen found by Schloesing's method was 0.125 , and by the copper-zinc method 0.162 per million of water. The original suspicion was thus confirmed. The lower result obtained by the use of

* This time is a good deal longer than that mentioned by Williams. It is perhaps unnecessarily long; but the condition of the solution naturally determines a very slow action. The disappearance of nitrites, as shown by metaphenylenediamine, ia in this case no safe indication of the completion of the reaction, as the amount of nitrous nitrogen will frequently be too small to give a reaction with this test. 
Nitrogen as Nitrates and Nitrites per million of Rain-water.

\begin{tabular}{|c|c|c|c|}
\hline Rains analysed. & $\begin{array}{l}\text { Schloesing's } \\
\text { method. }\end{array}$ & $\begin{array}{c}\text { Copper-zinc } \\
\text { method. }\end{array}$ & Difference. \\
\hline 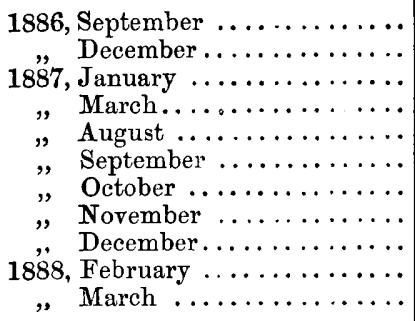 & $\begin{array}{l}0 \cdot 196 \\
0 \cdot 038 \\
0 \cdot 111 \\
0 \cdot 163 \\
0 \cdot 366 \\
0 \cdot 081 \\
0 \cdot 094 \\
0 \cdot 069 \\
0 \cdot 064 \\
0 \cdot 127 \\
0 \cdot 068\end{array}$ & $\begin{array}{l}0 \cdot 270 \\
0 \cdot 048 \\
0 \cdot 172 \\
0 \cdot 247 \\
0 \cdot 385 \\
0 \cdot 093 \\
0 \cdot 090 \\
0 \cdot 093 \\
0 \cdot 066^{*} \\
0 \cdot 229^{*} \\
0 \cdot 095^{*}\end{array}$ & $\begin{array}{l}0 \cdot 074 \\
0 \cdot 010 \\
0 \cdot 061 \\
0 \cdot 084 \\
0 \cdot 019 \\
0 \cdot 012 \\
0 \cdot 004 \\
0 \cdot 024 \\
0 \cdot 002 \\
0 \cdot 102 \\
0 \cdot 027\end{array}$ \\
\hline Mean 11 analyses...$\ldots$ & $0 \cdot 125$ & $0 \cdot 162$ & $0 \cdot 037$ \\
\hline
\end{tabular}

Nitrogen as Nitrates and Nitrites in 19 Monthly Rainfalls at Rothamsted (Schloesing's Method).

\begin{tabular}{|c|c|c|c|}
\hline & \multirow{2}{*}{ Rainfall. } & \multicolumn{2}{|c|}{ Nitrogen as nitrates and nitrites. } \\
\hline & & Per million. & Per acre. \\
\hline 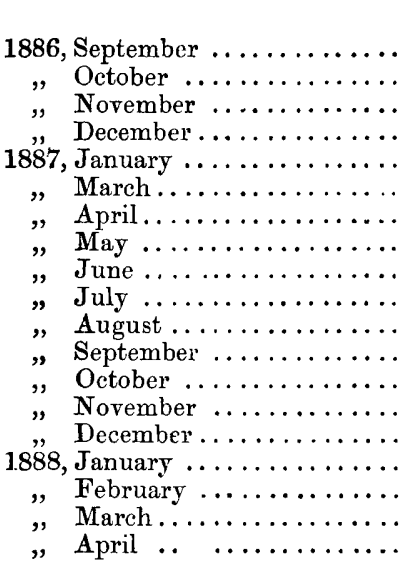 & $\begin{array}{l}\text { inches. } \\
1 \cdot 51 \\
3 \cdot 94 \\
2 \cdot 77 \\
4 \cdot 21 \\
2 \cdot 39 \\
1 \cdot 76 \\
1 \cdot 19 \\
2 \cdot 35 \\
0 \cdot 71 \\
0 \cdot 79 \\
1 \cdot 04 \\
3 \cdot 11 \\
1 \cdot 69 \\
3 \cdot 41 \\
1 \cdot 66 \\
0 \cdot 95 \\
0 \cdot 98 \\
3 \cdot 13 \\
2 \cdot 14\end{array}$ & $\begin{array}{l}0 \cdot 196 \\
0 \cdot 089 \\
0 \cdot 064 \\
0 \cdot 038 \\
0 \cdot 111 \\
0 \cdot 163 \\
0 \cdot 106 \\
0 \cdot 162 \\
0 \cdot 284 \\
0 \cdot 204 \\
0 \cdot 366 \\
0 \cdot 081 \\
0 \cdot 094 \\
0 \cdot 069 \\
0 \cdot 064 \\
0 \cdot 198 \\
0 \cdot 127 \\
0 \cdot 068 \\
0 \cdot 145\end{array}$ & $\begin{array}{l}\text { lb. } \\
0 \cdot 067 \\
0 \cdot 079 \\
0 \cdot 040 \\
0 \cdot 036 \\
0 \cdot 060 \\
0 \cdot 065 \\
0 \cdot 029 \\
0 \cdot 086 \\
0 \cdot 046 \\
0 \cdot 036 \\
0 \cdot 086 \\
0 \cdot 057 \\
0 \cdot 036 \\
0 \cdot 054 \\
0 \cdot 024 \\
0 \cdot 043 \\
0 \cdot 028 \\
0 \cdot 048 \\
0 \cdot 070\end{array}$ \\
\hline Mean of 19 months....... & $2 \cdot 09$ & $0 \cdot 111$ & $0 \cdot 052$ \\
\hline $\begin{array}{l}\text { Total } 12 \text { months, May, } 1887 \text {, to } \\
\quad \text { April, } 1888 \ldots \ldots \ldots \ldots \ldots \ldots\end{array}$ & $21 \cdot 96$ & $0 \cdot 124$ & $0 \cdot 614$ \\
\hline
\end{tabular}

These results were obtained with the less exact method first employed. 
Schloesing's method in the case of certain rain-waters was probably due, as already suggested, to a reduction of nitrates during the preliminary concentration of the water, and was thus no fault of the method itself.

When this error of deficiency was discovered, the nitrogen as nitrates and nitrites had already been determined during 19 months by Schloesing's method. Since May, 1888, the copper-zinc method, with its accompanying determination of the ready-formed ammonia in the rain, has been exclusively made use of. The results of these analyses are given on page 540 and below.

Nitrogen as Nitrates and Nitrites in 20 Monthly Rainfalls at Rothamsted (Copper-zinc Method).

\begin{tabular}{|c|c|c|c|}
\hline & \multirow{2}{*}{ Rainfall. } & \multicolumn{2}{|c|}{ Nitrogen as nitrates and nitrites. } \\
\hline & & Per million. & Per acre. \\
\hline 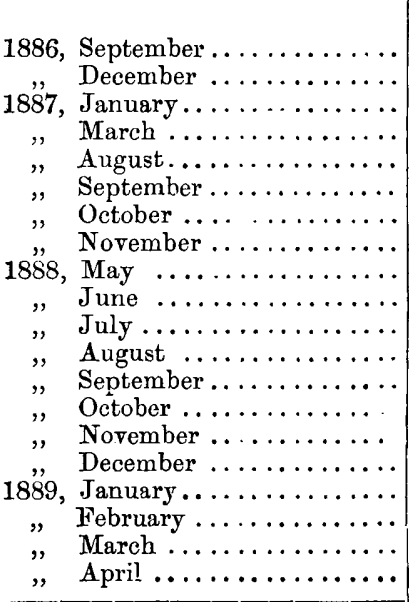 & $\begin{array}{c}\text { inches. } \\
1 \cdot 51 \\
4 \cdot 21 \\
2 \cdot 39 \\
1 \cdot 76 \\
1 \cdot 04 \\
3 \cdot 11 \\
1 \cdot 69 \\
3 \cdot 41 \\
1 \cdot 28 \\
4 \cdot 87 \\
3 \cdot 86 \\
3 \cdot 38 \\
1 \cdot 03 \\
1 \cdot 09 \\
4 \cdot 46 \\
1 \cdot 69 \\
1 \cdot 29 \\
1 \cdot 95 \\
1 \cdot 89 \\
2 \cdot 48\end{array}$ & $\begin{array}{l}0 \cdot 270 \\
0 \cdot 048 \\
0 \cdot 172 \\
0 \cdot 247 \\
0 \cdot 385 \\
0 \cdot 093 \\
0 \cdot 090 \\
0 \cdot 093 \\
0 \cdot 109 \\
0 \cdot 167 \\
0 \cdot 104 \\
0 \cdot 090 \\
0 \cdot 253 \\
0 \cdot 173 \\
0 \cdot 096 \\
0 \cdot 155 \\
0 \cdot 190 \\
0 \cdot 095 \\
0 \cdot 136 \\
0 \cdot 230\end{array}$ & $\begin{array}{l}1 \mathrm{~b} . \\
0 \cdot 092 \\
0 \cdot 046 \\
0 \cdot 093 \\
0 \cdot 098 \\
0 \cdot 091 \\
0 \cdot 065 \\
0 \cdot 034 \\
0 \cdot 072 \\
0 \cdot 031 \\
0 \cdot 184 \\
0 \cdot 091 \\
0 \cdot 069 \\
0 \cdot 059 \\
0 \cdot 043 \\
0 \cdot 097 \\
0 \cdot 059 \\
0 \cdot 055 \\
0 \cdot 042 \\
0 \cdot 058 \\
0 \cdot 129\end{array}$ \\
\hline Mean of 20 months,..... & $2 \cdot 42$ & $0 \cdot 138$ & 0.075 \\
\hline $\begin{array}{l}\text { Total } 12 \text { months, May, } 1888 \text {, } \\
\text { to April, } 1889 \ldots \ldots \ldots \ldots \ldots\end{array}$ & $29 \cdot 27$ & $0 \cdot 139$ & $0 \cdot 917$ \\
\hline
\end{tabular}

A comparison of the average amount of nitric nitrogen found by the two methods again shows that higher results were obtained by the copper-zinc method. Thus the average contents of 19 monthly samples (mean rainfall 2.09 inches) is 0.111 of nitric nitrogen per million by the Schloesing method; whilst the average of 20 monthly 
samples (mean rainfall $2 \cdot 42$ ) is $0 \cdot 138$ per million by the copper-zinc method. The excess by the latter method shown by these figures is also probably below the truth, as the waters analysed in the copperzinc series represent heavier rainfalls, and consequently weaker waters, than those analysed in the preceding series by Schloesing's method.

The average amount of nitrogen as nitrates and nitrites found by the more exact (copper-zinc) method is 0.138 per million. This is almost exactly the figure representing the arithmetical mean of Frankland's 34 analyses of individual rainfalls, namely, 0.14 per million. It is slightly higher than that found by Way, namely, 0.12 per million; the comparison with Way's results is apparently a fair one, as the average monthly rainfall in the case of his samples was 2.35 inches, and in the case of the present series, 2.42 inches.

In the next table the amount of nitrogen as ammonia, as well as that found as nitrates and nitrites, is given for the 12 months during which the copper-zinc method has been employed.

Nitrogen as Ammonia, and as Nitrates and Nitrites, in the Rainfall at Rothamsted during 12 months, 1888-89.

\begin{tabular}{|c|c|c|c|c|c|}
\hline & \multirow[b]{2}{*}{$\begin{array}{l}\text { Rainfall } \\
\text { (inches). }\end{array}$} & \multicolumn{2}{|c|}{ Per million of rain. } & \multicolumn{2}{|c|}{ Per acre (lbs.). } \\
\hline & & $\begin{array}{l}\text { Nitrogen } \\
\text { as } \\
\text { ammonia. }\end{array}$ & $\begin{array}{c}\text { Nitrogen as } \\
\text { nitrates and } \\
\text { nitrites. }\end{array}$ & $\begin{array}{c}\text { Nitrogen } \\
\text { as } \\
\text { ammonia. }\end{array}$ & $\begin{array}{l}\text { Nitrogen as } \\
\text { nitrates and } \\
\text { nitrites. }\end{array}$ \\
\hline 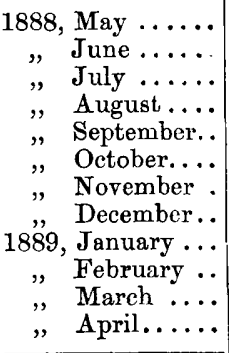 & $\begin{array}{l}1 \cdot 28 \\
4 \cdot 87 \\
3 \cdot 86 \\
3 \cdot 38 \\
1 \cdot 03 \\
1 \cdot 09 \\
4 \cdot 46 \\
1 \cdot 69 \\
1 \cdot 29 \\
1 \cdot 95 \\
1 \cdot 89 \\
2 \cdot 48\end{array}$ & $\begin{array}{l}0 \cdot 256 \\
0 \cdot 500 \\
0 \cdot 388 \\
0 \cdot 288 \\
1 \cdot 025 \\
0 \cdot 525 \\
0 \cdot 313 \\
0 \cdot 500 \\
0 \cdot 575 \\
0 \cdot 238 \\
0 \cdot 400 \\
0 \cdot 575\end{array}$ & $\begin{array}{l}0 \cdot 109 \\
0 \cdot 167 \\
0 \cdot 104 \\
0 \cdot 090 \\
0 \cdot 253 \\
0 \cdot 173 \\
0 \cdot 096 \\
0 \cdot 155 \\
0 \cdot 190 \\
0 \cdot 095 \\
0 \cdot 136 \\
0 \cdot 230\end{array}$ & $\begin{array}{l}0 \cdot 074 \\
0 \cdot 551 \\
0 \cdot 338 \\
0 \cdot 220 \\
0 \cdot 238 \\
0 \cdot 129 \\
0 \cdot 315 \\
0 \cdot 191 \\
0 \cdot 168 \\
0 \cdot 105 \\
0 \cdot 171 \\
0 \cdot 323\end{array}$ & $\begin{array}{l}0 \cdot 031 \\
0 \cdot 184 \\
0 \cdot 091 \\
0 \cdot 069 \\
0 \cdot 059 \\
0 \cdot 043 \\
0 \cdot 097 \\
0 \cdot 059 \\
0 \cdot 055 \\
0 \cdot 042 \\
0 \cdot 058 \\
0 \cdot 129\end{array}$ \\
\hline Whole year... & $29 \cdot 27$ & $0 \cdot 426$ & $0 \cdot 139$ & $2 \cdot 823$ & 0.917 \\
\hline
\end{tabular}

With a rainfall slightly above the average, the proportion of nitrogen as ammonia gives a mean of 0.426 per million or $2.823 \mathrm{lbs}$. per acre.* The nitrogen as nitrates and nitrites is at the same time 0.139

* This amount of nitrogen as ammonia is somewhat above the average of five years, already published (Trans., 1887, 502), namely $2 \cdot 41$ lbs. per acre. 
per million, or $0.917 \mathrm{lb}$. per acre. The total nitrogen present as ammonia, and as nitric and nitrous acid, is thus $3.74 \mathrm{lbs}$. per acre.

The amount of nitrous acid in the Rothamsted rain-water is extremely small, and only to be appreciated by the delicate naphthylamine test.

The quantities of nitric acid found by other investigators have been very various. The average result of the analyses made at seven agricultural stations in Germany and Italy in 1864-72 (J. Roy. Agric. Soc., 1881, 268), representing the rainfall of 13 years, is 0.47 per million of nitrogen as nitric acid, and 1.26 per million of nitrogen as ammonia, the total being $10.18 \mathrm{lbs}$. of nitrogen per acre per annum. At the Observatory at Montsouris (Paris) the average of 10 years is 0.70 of nitrogen as nitric acid, and 1.82 of nitrogen as ammonia per million of rain, the total being equal to $12.36 \mathrm{lbs}$. of nitrogen per acre per annum.

Results recently obtained at Lincoln, New Zealand, and at Tokio, in Japan, agree more closely with the Rothamsted figures. At Lincoln, Professor G. Gray finds, on an average of three years, $0 \cdot 15$ of nitric nitrogen, and 0.096 of ammoniacal nitrogen per million of rain; the total equal to $1.6 \mathrm{lb}$. of nitrogen per acre per annum. At Tokio, Kellner finds in one year's rain 0.085 per million of nitric nitrogen, or $1.02 \mathrm{lb}$. per acre. The nitrogen as ammonia in another year's rain was 0.126 per million, or $1 \cdot 78 \mathrm{lb}$. per acre.

Müntz and Aubin found only a minute trace of nitrates in rain and snow-water collected at the summit of the Pic du Midi (nearly $3000 \mathrm{~m}$. high); they suggest that nitrates are not produced in the atmosphere at elevations above those at which electrical discharges from clouds occur.

Müntz and Marcano (Compt. rend., 108, 1062) have analysed 121 rainfalls from Caracas (Venezuela); the mean proportion of nitric nitrogen was 0.578 per million, the maximum reached was 4.21 per million. Nineteen rainfalls from St. Denis (Réunion) gave a mean of 0.69 of nitric nitrogen per million. They conclude that the production of nitric acid in the atmosphere proceeds with much more energy in tropical countries.

Notes on the Analysis of Rain-water.

Rain-water is so seldom systematically analysed that our knowledge of its contents in various localities is very imperfect; it may perhaps, therefore, be of some use to describe very briefly the methods of analysis employed at Rothamsted.

If the average composition of rain-water is to be determined, it is most important that either the whole of the rain falling on a given 
area should form the sample examined, or that a sample representing the whole rainfall should be prepared by mixing together a fixed fraction of each rainfall. The plan adopted in preparing the monthly samples at Rothamsted has already been described. Averages obtained by taking the mean of many analyses, without regarding the relative quantity of the rainfalls which they represent, are necessarily inexast.

Ammonia.-When ammonia is determined by Nesslerising, the direction usually given is to place 400 c.c. or 500 c.c. of the water in the retort, and to distil two or more quantities of 50 c.c.; the total ammonia present is then ascertained by adding together the amounts found in the several distillates. This method may be convenient when nothing is known as to the quantity of ammonia present, but it must generally be attended with a loss of accuracy. The liability to error in comparing the tints given by the ammoniacal distillate, and by the standard solution of ammonia, is not inconsiderable, and is usually estimated as 5 per cent., though this may be reduced by practice. The possible proportion of this error is least at a certain depth of tint, about that given by 2 c.c. of the standard solution of ammonium chloride; with much weaker solutions, the possible error will assume considerably larger proportions. In following the method described above, we have the errors of at least two experiments included in the determination of the ammonia, and one or more of these errors may be proportionally great, from the extreme dilution of the later distillates.

The plan adopted at Rothamsted is to make one determination of ammonia in the whole of the distillate obtained, the strength of which is regulated by varying the amount introduced into the retort, so that it shall be equal to somewhere about 2 c.c. of the standard ammonia solution. A 150 c.c. cylinder is first filled with the rainwater, and 3 c.c. of Nessler's reagent added; the depth of tint indicates what quantity of rain will be required for distillation. The retort and condenser having been freed from ammonia by boiling distilled water and a little magnesia in the retort, the measured amount of rain-water is added to the (cooled) contents of the retort, taking care that the final volume does not exceed 600 c.c. ; distillation is then continued till a 150 c.c. cylinder is filled. The determination of ammonia is made in this distillate in the usual way. The five years' determinations of ammonia already referred to were made in this manner. When nitric acid is also to be determined, the ready formed ammonia is obtained in the manner described above.

Nitric Acid.-The general mode of determining nitric acid by means of the copper-zinc couple has been already given; the preparation of the couple is the only point requiring further detail. For the 800 c.c. of boiled rain-water I employ six strips of zinc foil, 4 inches long by 
$1_{4}^{1}$ inches wide; the strips are bent at right angles along their centre to obtain stiffness. The couple is prepared in a series of five beakers, containing respectively a dilute solution of sodium hydrate, very dilute sulphuric acid, 3 per cent. solution of copper sulphate, ordinary distilled water, distilled water free from ammonia. Through these five beakers the zinc-foil is successively passed. It is rinsed both after the alkali and acid, but after the copper has been deposited the strips are simply drained, and carefully placed in the distilled water, it being difficult to rinse without removing the copper. The couple should be entirely submerged when placed in the rain-water.

Chlorine.-The method of estimation employed is the one generally made use of in water analysis, namely, titration with solution of silver nitrate, using potassium dichromate as an indicator. The proportion of chlorine in rain is generally too small to be determined with accuracy in the unconcentrated water. Moreover, some rain-waters give at once an orange tint with the reagents employed, giving rise to the idea that chlorine is absent: this orange tint is not discharged by the addition of a chloride. The method adopted at Rothamsted is to add 5 c.c. of lime-water, free from chlorine, to 1 litre of rain-water, and to concentrate the water in an open basin in a quiet room to less than a quarter litre. When cold, the water is filtered through a washed filter into a quarter-litre flask, diluted to a quarter litre, and then used for the determination of chlorine. In water thus prepared a normal reaction is always obtained.

Sulphuric Acid.-The rain used for the determination of sulphates is specially collected in a glass funnel, having a small piece of asbestos cloth in the pipe; no vulcanised caoutchoue is employed for connections. $10-15$ lbs. of the water are concentrated to a small bulk in a retort, and then filtered through Swedish paper previously washed with hydrochloric acid. Sulphuric acid is then gravimetrically determined in the filtrate with barium chloride. The concentration in a retort is essential, as gas flames are a constant source of sulphuric acid. 